Journal of Positive Sciences (JPS), Issue (2), Volume (2021)

\title{
Performance Analysis of DPSK Technique for Optical Transmission Systems
}

\author{
Zeyad Taha Yaseen ${ }^{1}$ \\ ${ }^{1}$ Baghdad college of Economic, Sciences university, Baghdad, Iraq \\ 1 engzeyad1971@yahoo.com
}

\section{Abstract}

The long-distance high data rate transmission is accompanied by many transmission defects, which reduce the performance of optical communication systems. Therefore, due to the need to increase data capacity for the end user, signal regeneration techniques were used to mitigate these non-linear defects in the electric or optical field. Several techniques used to modify the optical signal, which is the possible solution to reduce the limit of non-linear transmission defects, especially before converting the signal from the optical field to the electric field. Since most of the techniques used to reduce the attenuation in the optical signal do not have the ability to reduce the error rate to reach a bit error rate (BER) less than 10-10 with a transmission capacity less than $-10 \mathrm{dBm}$. In this paper, the performance evaluation of DPSK has been validated for its adequate use in transmission systems. Nevertheless, the performance of the DPSK optical system was assessed to rely on a different coding format such as: Return to Zero (RZ) \& Non-Return to Zero (NRZ-DPSK). The system is designed to withstand high data rate on longdistance optical transmission systems. The system investigated was simulated with OptiSystemTM 13.0 commercial software. The investigated system demonstrated the ability to mitigate nonlinear impairments from the noisy optical DPSK system with high bit-error rate (BER) improvement at low power transmission. Optical DPSK demonstrates the ability to send high-rate data transmission systems for use in the next generation of optical networks.

Keywords: Dual Phase Shift keying, Return to Zero, Optical Transmission Systems, Non-Return to Zero.

Manuscript received on: 05.03.2021

Accepted on: 12.04.2021

Published on: 02.05.2021

Issue DOI: doi.org/10.52688/iss2

Manuscript DOI: doi.org/10.52688/iss2/ASP17354

\section{INTRODUCTION}

Since the last two decade, too many researchers work on developed various techniques to improvement the performance of the optical communication systems, to send large amount of data rate over fiber link channel [1]. In fact, this development emergent due to the need for high speed optical network to support fast internet for multimedia applications and broad band wireless access. The use of modern optical communication technologies that provide the use of laser signals is less loss and higher bandwidth compared to microwave communication [2, 3]. The high advance modulated signal format techniques currently used to improve the optical system capacity. However, There are three main types of multiple access approaches that are used in optical communication systems: TDMA, WDMA and OCDMA. have been developed to multiplex the transmitted from different modulated channel to send it through single fiber channel[4, 5]. Where, the WDMA technique has several advantages such as: dedicated channels provided, simultaneous users allowed, and high bandwidth efficiency. But the main disadvantage of the WDMA systems is the nonlinear effect and the dispersion, which considered as the most restriction of optical communication systems [6, 7]. To mitigate the non-linear and the dispersion effects, several modulation techniques used in the transmitter of the optical system to do so. While some researcher work on including dispersion compensation fiber [8] to reduces the dispersion effects. In fact the optical DPSK techniques shows the capability to reduce the effect of both the non-linear effect and the dispersion in fiber link specially when the system used for long-haul transmission[9-11]. However, many researchers proposed several solutions to redact the effect of high-speed optical network impairments. The searches work on changing the channel equality spacing, including fiber dispersion compensation as well including digital modulation techniques [12-14]. As far as we know, the performance evaluation of the RZ-DPSK \& NRZ-DPSK techniques has not yet been addressed without using signal compensation in long-range non-linear dispersive optical channels. In this 
paper, the study is based on a comparison between the optical RZ-DPSK as well as the NRZ-DPSK format without using a fiber compensator. This article is organized as follows: In section 2 describe the simulation setup of the DPSK optical system. Section 3 is intended for the evaluation of the DPSK visual system. Finally, the conclusions are represented in section 5 .

\section{SIMULATION SETUP OF OPTICAL DPSK SYSTEM}

Virtual private network (VPN) is established for tunneling the connections over the public network where no other candidate out of the virtual private network can participate the connections without prior permission. This kind of protection is proven good performance in protection connections over bigger networks including internet. Network includes various types of activities which may demand specific requirements of bandwidth and routing process. The proofs of the principle setup model Optical DPSK System is shown in Figure 1. As conventional optical system consists of the transmitter, link channel and the receiver. Figure 1 shows the Optical DPSK system, which is designed by the OptiSystem software for single channel.

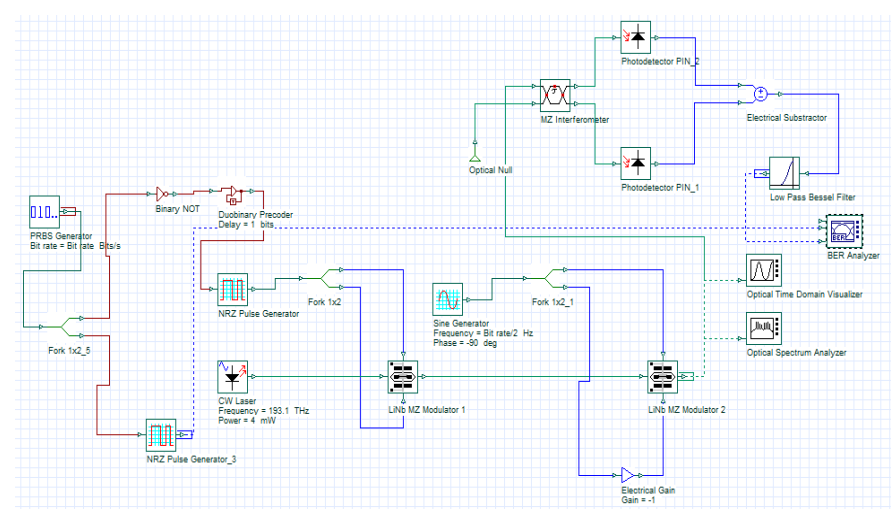

Figure 1: Typical Simulations Optical DPSK System.

The following subsection described the consists parameter of the transmitter, link channel and the receiver components.

\subsection{Optical DPSK Transmitter}

The RZ-DPSK optical signal format transmitter includes a $\mathrm{CW}$ laser source, a random binary sequence generator, a pocket generator, a programmer, and two Mach-Zehnder modifiers. Since the optical DPSK modulation carries data in the optical phase, the most accurate modulator configuration depends on the phase modulator. As the phase changer modifies only the phase of the optical signal, resulting in a fixed amplitude [15]. Still, the laser source generates a beam of a continuous wave laser signal (frequency $1550 \mathrm{~nm}$ and energy), which is applied as a holder to modify the electrical data signal in the modulator. Besides, PRBS generates false random binary sequences. These sequences are used to create the RZ electric bit stream. The Mach Zehnder Modulator (MZM) modifies electrical data using the optical transmission produced by the $\mathrm{CW}$ laser. Two Mach-Zehnder modifiers are used in the RZ-DPSK transmitter, one to adjust the data phase and the other to adjust the hourly capacity to sculpt the RZ pulse. The last part of the transmitter is the Sine generator, a unit that generates an electric sinusoidal waveform signal. Using this unit and the MZM unit. However, the external phase encoder, the electrical NRZ signal must be pre-encoded by the DPSK encoder. In a DPSK encoder, NRZ data is first converted by the NOT gateway and then combined by the XOR gateway with the one-bit delay version. The encoded electrical DPSK signal is then employed to drive the electric optical phase modulator to generate a DPSK optical signal. To this step, an NRZ-DPSK optical signal is generated as presented in Figure (2.a). To generate an RZ-DPSK optical signal, the optical NRZ-DPSK signal is modified by a clock signal at the same data rate as the electrical signal through an electro-optical intensity rate as presented in Figure (2.b).

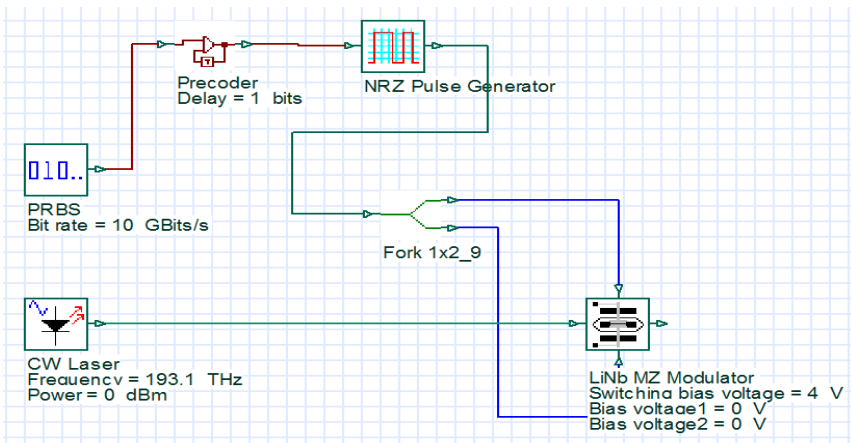

Figure 2 (a): NRZ-DPSK Modulator 


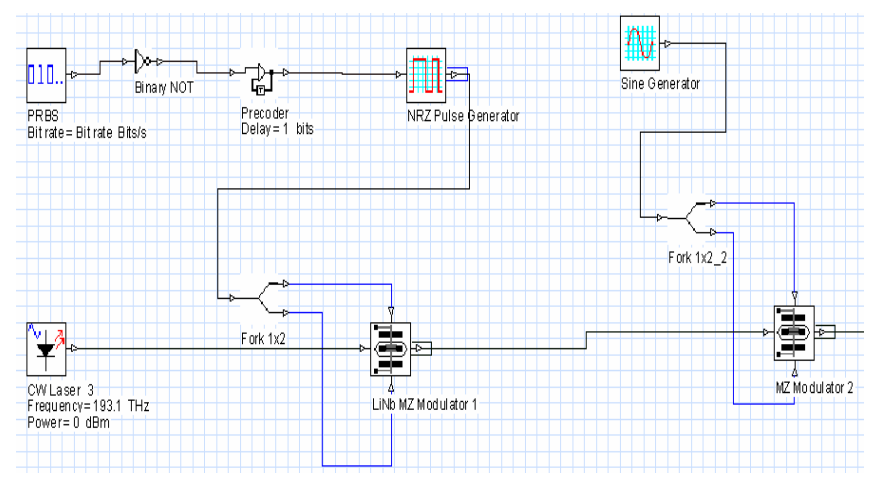

Figure 2 (b): RZ-DPSK Modulator

\subsection{Optical DPSK Channel}

After the signal is emerged from the end of the transmitter, it lunched in the optical fiber channel. In this work, ITU-T G.652 optical fibers are used because they are the optimal type of fiber versus nonlinear fiber channel compared to other types of optical fibers [16]. Simulation parameters of the transmission link is illustrated in Table (1) as shown below.

Table 1: Simulation parameters of the transmission link

\begin{tabular}{|l|l|}
\hline \multicolumn{2}{|l|}{ ITU-T G.652 Fiber, 60 km span length } \\
\hline SMF parameters & 0.2 \\
\hline$\alpha(\mathrm{dB} / \mathrm{km})$ & 17 \\
\hline $\begin{array}{l}\text { Dispersion parameter D } \\
\text { (ps/(nm.km)) }\end{array}$ & 0.075 \\
\hline $\begin{array}{l}\text { Dispersion slope S } \\
\text { (ps/(km.nm2)) }\end{array}$ & 70 \\
\hline \begin{tabular}{l} 
Effective area ( $\mu \mathrm{m} 2)$ \\
\hline DGD parameter (ps)
\end{tabular} & 0.1 \\
\hline $\begin{array}{l}\text { DCF parameters } \\
\alpha(\mathrm{dB} / \mathrm{km})\end{array}$ & 0.5 \\
\hline $\begin{array}{l}\text { Dispersion parameter D } \\
\text { (ps/(nm.km)) }\end{array}$ & -85 \\
\hline $\begin{array}{l}\text { Dispersion slope S } \\
\text { (ps/(km.nm2)) }\end{array}$ & 0.3 \\
\hline \begin{tabular}{l} 
Effective area ( $\mu \mathrm{m} 2)$ \\
\hline DGD parameter (ps/)
\end{tabular} \\
\hline
\end{tabular}

\subsection{Optical DPSK Receiver}

On the receiver side, the received signal is employed to the RZ-DPSK receiver in order to recognize it and convert it into an electrical signal. In the RZ-DPSK receiver, the MachZehnder interferometer optically removes the signal with a bit delay in one arm, comparing the step between bit times to determine if the transition has occurred, followed by 2 optical detectors on each Interferer exit port. The difference between the received currents from the two photodiodes is filtered by a 4th order Bessel filter of $7.5 \mathrm{GHz}$ cutoff frequency as shown in Figure (3).

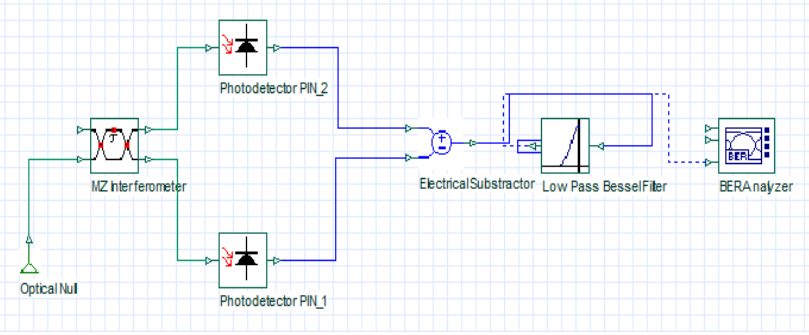

Figure 3: The receiver of DPSK modulation format with direct detection Technique. The Simulation parameters of the receiver are presented in Table (2).

Table 2: The parameters of the receiver

\begin{tabular}{|l|l|}
\hline Parameter & Value \\
\hline Xcoupler & coupling coefficient (0.5) \\
\hline Time delay (TD) & $\begin{array}{l}\text { Delay=1/Bit rate=100e-012 } \\
\text { s }\end{array}$ \\
\hline Photodetector & PD \\
\hline Type & 5 \\
\hline Gain & $1 \mathrm{~A} / \mathrm{W}$ \\
\hline Responsivity & 0.9 \\
\hline Ionization rate & $10 \mathrm{nA}$ \\
\hline Dark current & $1 \mathrm{e}-22 \mathrm{~W} / \mathrm{Hz}$ \\
\hline Thermal noise & 4 th order Bessel filter \\
\hline Electrical low pass filter & $7.5 \mathrm{GHz}$ \\
\hline Order &
\end{tabular}


Journal of Positive Sciences (JPS), Issue (2), Volume (2021)

\section{THE EVALUATION OF OPTICAL DPSK SYSTEM}

In this section, we will evaluate the performance of the DPSK optical system using a simulation program, OptiSystem v13. A simple diagram of one active channel is shown in Figure. 1. The spectral channel width is $50 \mathrm{GHz}$. The simulation was performed at a rate of $10 \mathrm{Gbit} / \mathrm{s}$ for a distance of $50 \mathrm{~km}$ using the standard single-mode optical fiber (SMF) ITU-T G.652 [16]. In simulation setup we activate all attenuation such as: $\alpha$ fiber attenuation $(0.2 \mathrm{~dB} / \mathrm{km})$, Dispersion (17 ps/ $\mathrm{nm} \mathrm{km}$ ), non-linear effects, four-wave mixing and auto phasing. The attenuation was activated according to the typical industrial values to simulate the real environment as quickly as possible. Table (4) shows the parameter used in simulation setup including SMF parameter and dispersion parameters. The system performance was distinguished by reference to BER and eye pattern.

Table 4: The parameters for the receiver

\begin{tabular}{|l|l|}
\hline Parameter & Value \\
\hline Xcoupler & $(0.5)$ coupling coefficient \\
\hline Time delay (TD) & $\begin{array}{l}\text { Delay=1/Bit rate=100e-012 } \\
\text { s }\end{array}$ \\
\hline Photodetector & PN \\
\hline Type & 5 \\
\hline Gain & $1 \mathrm{~A} / \mathrm{W}$ \\
\hline Responsivity & 0.9 \\
\hline Ionization rate & $10 \mathrm{nA}$ \\
\hline Dark current & $1 \mathrm{e}-22 \mathrm{~W} / \mathrm{Hz}$ \\
\hline Thermal noise & $4.5 \mathrm{GHz}$ order Bessel filter \\
\hline Electrical low pass filter & \multicolumn{2}{|l}{} \\
\hline Order & 7.5 \\
\hline Cutoff frequency & \\
\hline
\end{tabular}

Figure 5 and Figure 6 shows the variation of BER as a function of fiber length for the 4 active user and 8 active users for NRZ-DPSK system. The data rate carried by the whole systems is $40 \mathrm{~Gb} / \mathrm{s}(10 \mathrm{~Gb} / \mathrm{s} \times 4$ users $)$.

The simulation results show that the BER of the 4-active user of NRZ-DPSK for the first channel at $100 \mathrm{~km}$ is $2.9 \times 10-9$, where are the lunched power equal to $-5 \mathrm{dBm}$. While the BER of RZ-DPSK for the first channel at $100 \mathrm{~km}$ is $1.48 \times 10-11$. However, the simulation result shows that the increase of the lunched power will obviously decrease the BER of the transmission system. The increase of the BER is due to present of dispersion and attenuation as increase the fiber link. So, to achieve high data transmission long distance communication link, the maximum fiber length should be as short as possible.

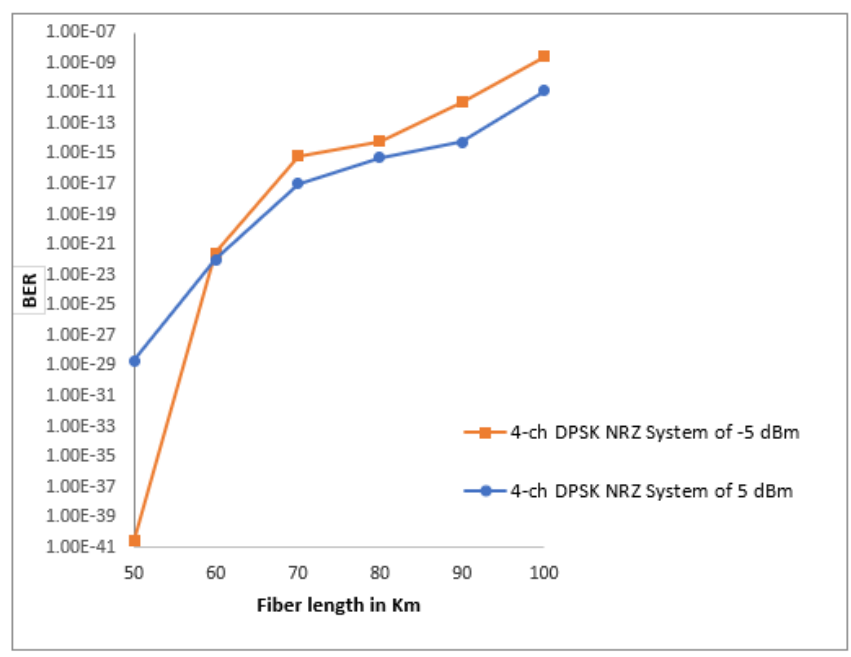

Figure 5: BER vs. the fiber length of 4 active users for DPSK System with RZ-DPSK and NRZ-DPSK.

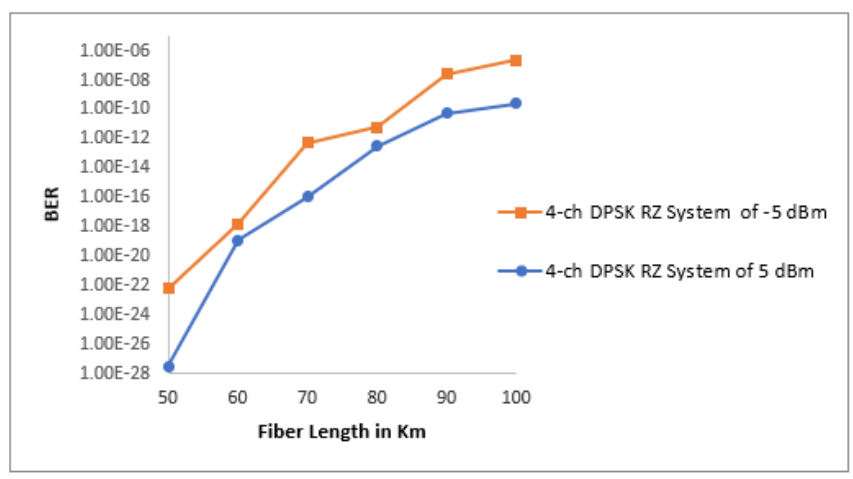

Figure 6: BER vs. the fiber length of 4 active users for DPSK System with RZ-DPSK and NRZ-DPSK.

The performance Analysis of the of $8 \times 10 \mathrm{~Gb} / \mathrm{s}$ Optical RZDPSK \& NRZ-DPSK modulation format with direct detection at $50 \mathrm{GHz}$ spacing channel respectively are 
Journal of Positive Sciences (JPS), Issue (2), Volume (2021)

presented. The performance comparisons between these techniques in terms of BER versus fiber length are simulated and presented. The systems evaluated and tested for different input power (-5 and $5 \mathrm{dBm})$ as shown in figure (7). The BER of the first channel of the 8 active channels equal to $2.29 \times 10$ 14 when the launched system power equal to $5 \mathrm{dBm}$ and the fiber length is $50 \mathrm{Km}$.

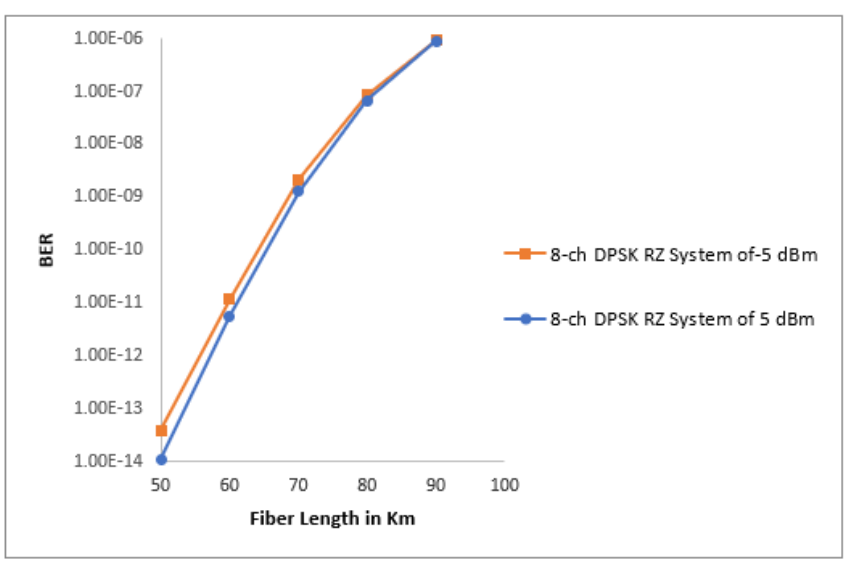

Figure 7: BER vs. the fiber length of 8 active users for DPSK System with RZ-DPSK.

The eye pattern for eye diagram of RZ-DPSK for 8 active users for $50 \mathrm{~km}$ transmission link with $\mathrm{BER}=2.29 \times 10-9$ shown in Figure 8.

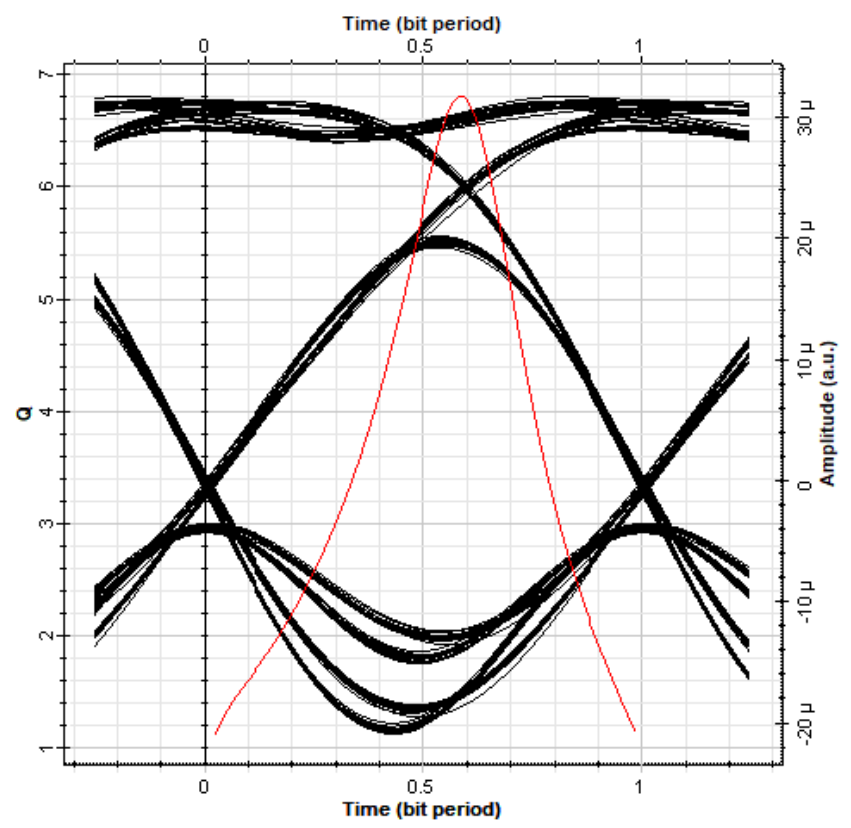

Figure 8: Eye Diagram of RZ-DPSK at $80 \mathrm{~Gb} / \mathrm{s}$ for $50 \mathrm{~km}$ of BER = $2.29 \times 10^{-9}$.

Figure (9) represents the Q-factor various the applied power for RZ- DPSK \& NRZ-DPSK with a bit rate of $40 \mathrm{~Gb} / \mathrm{s}$. The simulation results show in Figure (9) that the RZ-DPSK system has better performance than NRZ-DPSK as increase the launched power. The system of RZ-DPSK shows that the Q-factor equal to 10.5 when the launched power equal to 15 $\mathrm{dBm}$.

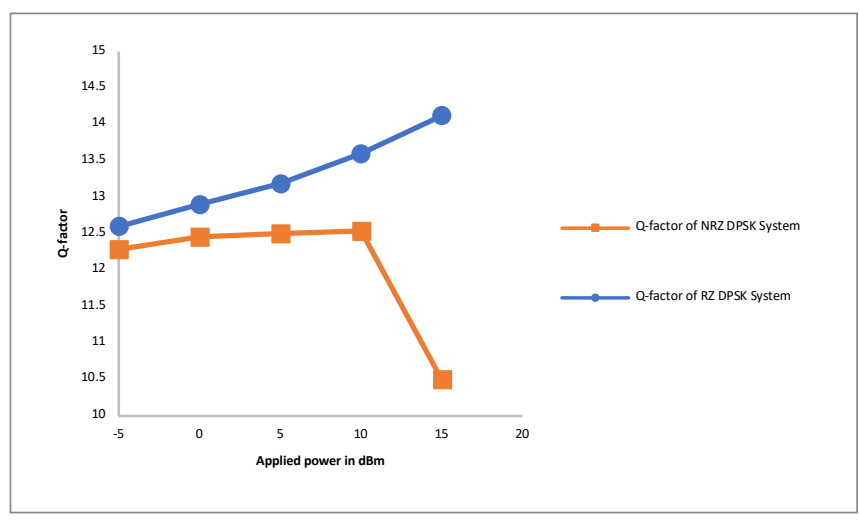

Figure 9: Applied Power versus the fiber length of 8 active users for DPSK System with RZ-DPSK \& NRZ-DPSK.

The performance of the RZ-DPSK and NRZ-DPSK systems are simulated using direct detection techniques. The tests are carried out at the rate of $40 \mathrm{~Gb} / \mathrm{s}$ and $80 \mathrm{~Gb} / \mathrm{s}$ for $50 \mathrm{~km}$ with laser power of $5 \mathrm{dBm}$. The eye pattern diagram of the NRZDPSK and RZ-DPSK systems employing direct detection scheme are shown in Figures 10 and Figure 11 respectively.

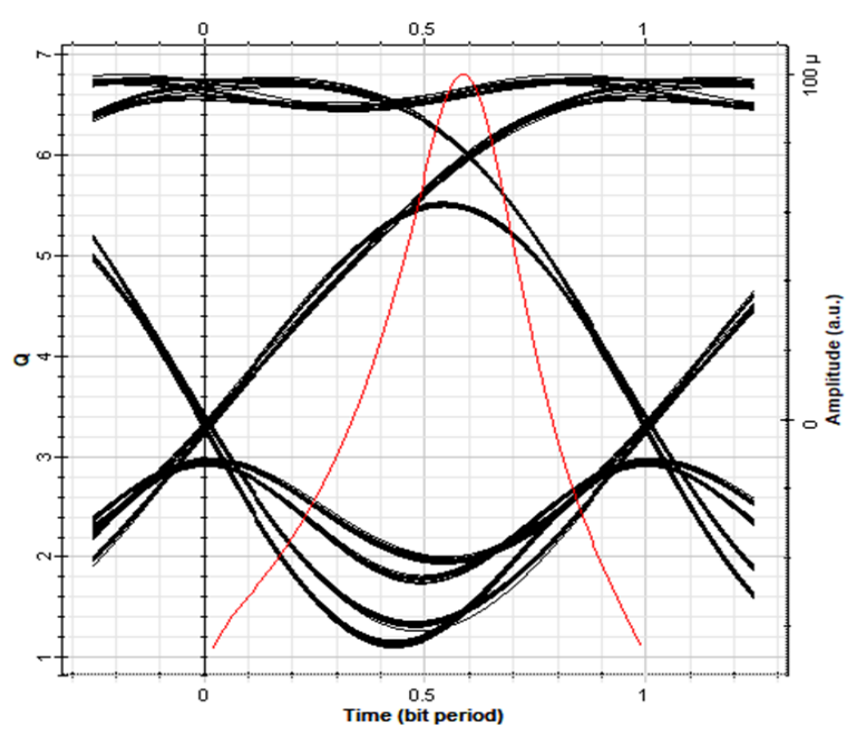

Figure 10: Eye Diagram of NRZ-DPSK at $40 \mathrm{~Gb} / \mathrm{s}$ for $100 \mathrm{~km}$ of $\mathrm{BER}=2.6 \times 10^{-9}$. 


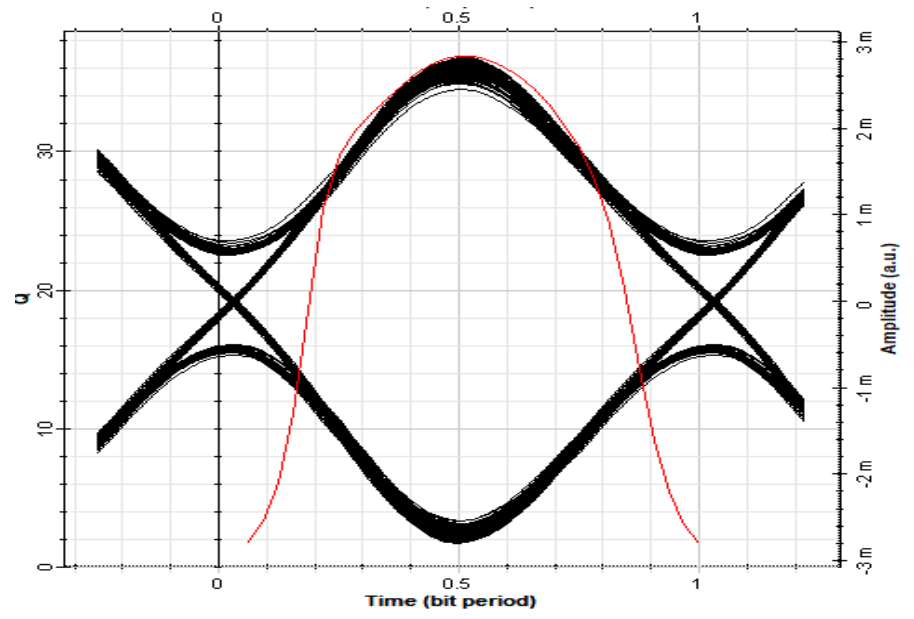

Figure 11: Eye Diagram of RZ-DPSK at $40 \mathrm{~Gb} / \mathrm{s}$ for $100 \mathrm{~km}$ of

$$
\mathrm{BER}=1.48 \times 10^{-11} \text {. }
$$

\section{CONCLUSION}

In this work, the performance analysis of 4 and 8 active channels of the RZ-DPSK \& NRZ-DPSK with direct detection at $10 \mathrm{~Gb} / \mathrm{s}$ as transmission bit rate for each channel have been presented. The Optical DPSK technique shows the Significantly improved the BER with a low energy fine with high Q factor values. From the extracted result, we obviously note the performance of the of the RZ-DPSK is better than of NRZ-DPSK system. This is due to the pulse duration of the RZ-DPSK system, which is smaller than of the NRZ-DPSK system. The DPSK system shows the ability to carry high data rate for long-haul distance without using any regeneration technique to reduce the nonlinearity effect of the link channel. However, the optical DPSK system can be used for the next generation optical communication systems.

\section{REFERENCES}

[1] H. A. Mahmood and R. K. J. I. J. E. T. Ahmed, "Fiber bragg grating and channel spacing effect in WDM radio over fiber system using DPSK modulation format," vol. 7, pp. 218-22, 2018.

[2] J. B. Padhy and B. Patnaik, "DPSK and Manchester coding for Inter-satellite Optical Wireless Communication systems," in 2018 IEEE 5th International Conference on Engineering Technologies and Applied Sciences (ICETAS), 2018, pp. 1-5: IEEE.

[3] H. Kaushal, G. J. I. c. s. Kaddoum, and tutorials, "Optical communication in space: challenges and mitigation techniques," vol. 19, no. 1, pp. 57-96, 2016.

[4] T. H. Abd et al., "Performance improvement of hybrid SCM SAC-OCDMA networks using multi-diagonal csode," vol. 7, no. 11, pp. 1262-1272, 2012.

[5] T. T. Pham, H.-S. Kim, Y.-Y. Won, and S.-K. J. J. o. t. O. S. o. K. Han, "Bidirectional 1.25-Gbps WDM-PON with Broadcasting Function Using A Fabry-Perot Laser Diode and RSOA," vol. 12, no. 4, pp. 359-363, 2008.
[6] T. H. Abd, "Development of Novel OCDMA Codes for FTTH Network," School of Computer and Communication Engineering, 2013.

[7] P. A. J. O. S. Baziana and Networking, "Resource allocation mechanism for efficiency improvement in WDM networks: An analytical comparison study," vol. 33, pp. 15-24, 2019.

[8] D. Malik, G. Kaushik, and A. J. J. o. O. C. Wason, "Effects of Diverse Dispersion Compensation Formats at Different Data Rates in Light-Wave System," vol. 40, no. 3, pp. 273-280, 2019.

[9] B. Ait Ahmed, O. Aghzout, M. Chakkour, F. Chaoui, and A. J. I. J. o. O. Naghar, "Transmission Performance Analysis of WDM Radio over Fiber Technology for Next Generation Long-Haul Optical Networks," vol. 2019, 2019.

[10] H. K. Gill, G. K. Walia, and N. S. J. O. Grewal, "Performance analysis of mode division multiplexing ISOWC system using Manchester, DPSK and DQPSK modulation techniques," vol. 177, pp. 93-101, 2019.

[11] R. Kouser and S. Singh, "Analysis and Reduction of Fiber Non-linearity in Optical Communication System," in Applications of Computing, Automation and Wireless Systems in Electrical Engineering: Springer, 2019, pp. 987-995.

[12] H. U. Manzoor, T. Manzoor, A. Hussain, M. H. Aly, S. J. I. J. o. S. Manzoor, and T. o. E. E. Technology, "FWM Reduction Using Different Modulation Techniques and Optical Filters in DWDM Optical Communication Systems: A Comparative Study," pp. 110, 2019.

[13] E. Pincemin, N. Brochier, M. Selmi, O. Z. Chahabi, P. Ciblat, and Y. J. I. P. T. L. Jaouën, "Novel blind equalizer for coherent DP-BPSK transmission systems: Theory and experiment," vol. 25, no. 18, pp. 1835-1838, 2013.

[14] A. K. Mishra, "Evolution of Optical Fiber Technologies," ed: Application Note, Sterlight Technologies Limited, www. sterlitetech. com, India, 2013. 